\title{
Design of Thermally Constrained High-Frequency Induction Heating System
}

\author{
Arun Kumar Paul, Senior Member IEEE
}

\begin{abstract}
One of the most prominent application areas of induction heating principle is for sealing of caps of plastic and glass containers. It is increasingly being used to seal containers with extremely wide range industrial products. The process ambience around the controller for sealing of bottles containing different types of products could be different. Such prospects, often, could act as constraints for design of power controllers. Dust prone environment prevailing in processes such as for sealing nutraceuticals, coffee, a few pharma products, etc. recommends use of air-tight enclosure. It does not have any ventilation, even the natural air movement inside or the free convection is restricted. This article proposes that the internal convection could still be made effective by creating requisite buoyant force where both power converter topology and component engineering could play important roles. The topology should optimally reduce the power loss and surface temperature of components should be high. The proposed idea has been validated by designing a zero-ventilated $1.5 \mathrm{~kW}, 50 \mathrm{kHz}$ induction heating system that includes the induction coil head.
\end{abstract}

Keywords - Buoyancy driven internal convection, component engineering, ingress protection (IP), series resonant inverter (SRI), zero voltage zero current switching (ZVZCS).

\section{INTRODUCTION}

$\mathrm{Q}$ UANTITATIVELY, on-line sealing of containers using thin aluminum foils has been the most prominent application domain [1]-[6] of induction heating principle [7]-[11]. It is increasingly being used as a packaging solution for extremely diverse industrial products, such as, for sealing of containers with pharmaceutical, petroleum, food and beverage items, etc. Certain critical applications demand distinct operating features from a controller. The process ambience of several pharma, food, nutraceutical industries are dust prone. The powder material being sealed should not enter the controller. On the other hand, for sealing of dairy products, the enclosure needs frequent cleaning by water jet to remove thick layer of deposition of milky substance on the body of the enclosure. Therefore, for these applications, there is need for air and water-tight power controllers. The enclosure houses the complete control unit plus the coil head (see Fig. 1). The operating frequency of the converter is high and its power rating is moderate. Controlling the temperature rise of different components in a constrained environment could be a challenge.

Power loss is an integral part in any high-frequency power converter. For passive components, in particular, it is difficult to remove such loss from zero ventilated enclosures because the air movement is restricted. Addition of fan may not boost the convection features inside, rather, power loss in it could affect adversely [12]. Transfer of heat by convection from a typical source to top metallic surface of enclosure could, somewhat, be made effective if significant buoyant force is created inside [13]; its magnitude depends on the temperature difference in air inside. E.g., the induced air speed for $10{ }^{\circ} \mathrm{C}$ of temperature difference in a $5 \mathrm{~m}$ high room is significant at $1.3 \mathrm{~m} / \mathrm{s}$ [14]. In a power controller, there are several heat sources placed in different layers inside the enclosure. To make the heat removal process buoyancy driven the heat loss of each component should not be confined within, it is possible if the respective thermal resistance is small. The derating of components appears to be mandatory. The buoyant force is effective if the surface temperature of each heat source or component is large. The component engineering could play critical role [15], [16] where the study on loss characteristics and heat conduction features is needed. The design criteria would be to not only to restrict the power loss but also to enhance the heat removal means from each source. Therefore, the design aspects to focus on are,

1. Minimizing the total power loss [17]

2. Optimally reduce power loss per component, and

3. Ensure superior distribution of the power loss inside the cabinet - have more loss centers.

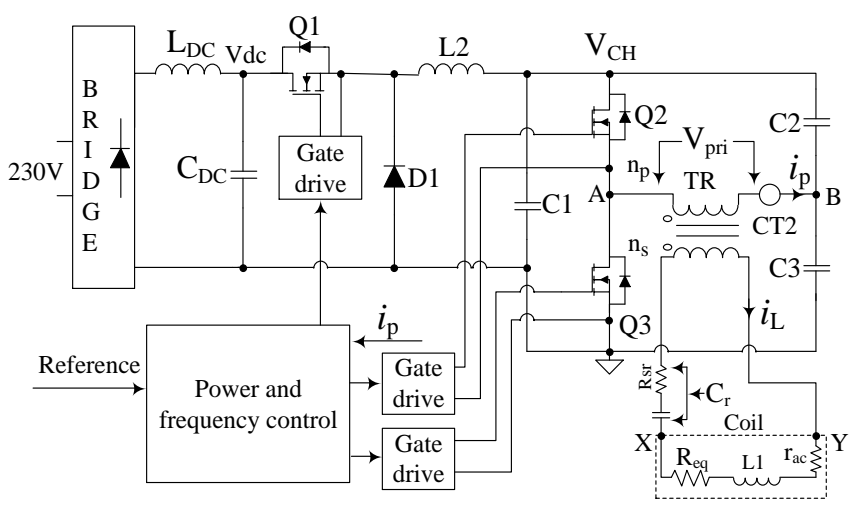

Fig. 1: Schematic diagram of a typical frequency and power control circuit for induction heating system

In a controller incorporating frequency control to effectively deliver large power to load the number of heat sources are many, each having different loss and thermal characteristics. When the coil head L1, placed at the bottom, becomes an integral part of air-tight enclosure the power losses in active and passive components are evenly matched. The heat removal from passive components is guided by buoyant force whereas for active components the heat loss could be removed by using a heat sink [18] physically connected to wall(s) of enclosure. 
Primarily, to reduce the heat load on weak thermal circuit the power loss needs to be minimized. This article elaborates that for continuous-duty reliable operation of the controller in airtight enclosure, both adoption of suitable topology and selection of components would play critical roles. The article is structured as follows: Section II discusses on basic functioning of wide range induction sealing systems. Section III discusses on the role of inverter topology both for power loss and its distribution. Section IV details the approach for selecting active and passive components. Finally, Section V, through prolong heat run test, validates the design of $1.5 \mathrm{~kW}, 50 \mathrm{kHz}$ ZVZCS water and air-tight power controller for sealing wide range containers.

\section{Wide RANGE INDUCTION CAP SEALING}

The diagram of a typical power delivery circuit in induction cap sealing is shown in Fig. 1. Power is transferred to thin aluminum foil (see Fig. 2) when it travels below the energized coil. Placed inside the cap, the foil assembly consists of four components. The foil is attached to a cardboard using paraffin wax and fine layer of polyethylene terephthalate (PET) film is laminated on its bottom layer. The sealing process is initiated when power is transferred to foil by electro-magnetic induction to evaporate wax at top and melt PET layer at bottom. The molten PET film creates a strong bond between foil and lip of container. The cardboard gets detached when the wax is evaporated from top surface of foil. The quantum of power $P_{\text {OUT }}$ transferred to foils depends on four parameters,

$P_{\mathrm{OUT}}=K_{c} L_{1} i_{L}^{2} f_{s}=i_{L}^{2} R_{e q}$

$\mathrm{L} 1$ is inductance value of coil, $i_{\mathrm{L}}$ is current through it, $f_{\mathrm{s}}$ is frequency of $i_{\mathrm{L}}$ and the parameter $K_{\mathrm{c}}$ depends on coupling between the coil and foil(s). $R_{\text {eq }}$ represents the total load of foil(s) reflected to the tank circuit. The value of $i_{\mathrm{L}}$ is maintained at constant value because of following reasons:

1. The quality of sealing would depend only on one variable i.e., $K_{\mathrm{c}}$. In cap sealing the value of $\mathrm{L} 1$ and $f_{\mathrm{s}}$ do not drift much with application of load, and,

2. In air-tight system, any increase in $i_{\mathrm{L}}$ would increase the HF power loss, particularly, in litz-wire based coil head that could cause further rise in temperature.

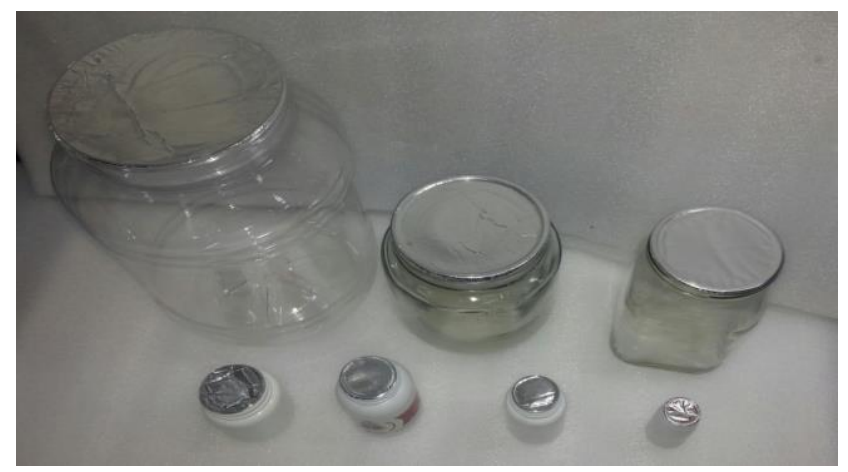

Fig. 2: Modern induction sealers need to cater wide range applications

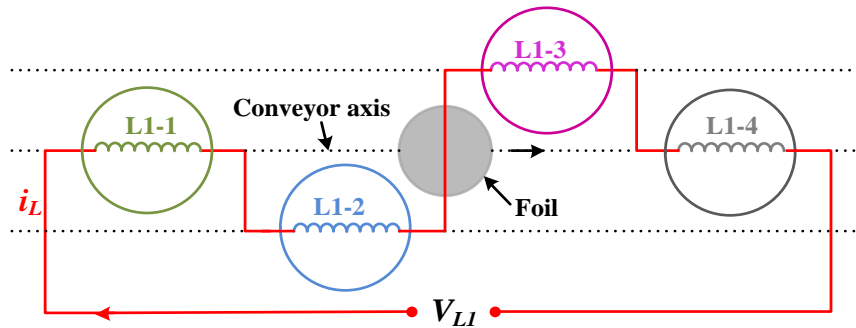

Fig. 3: Typical arrangement of moving foil under multi-head multi-axis coil head, it ensures superior energy distribution on foil surface

Induction sealing is now being used as a packaging solution for vast range of industrial products where the dimension of foils varies widely (see Fig. 2). The controller should be able to cater such wide range need where geometry of coil could play important role. The transferred power $P_{\text {OUT }}$ is supposed to perform two activities simultaneously - bonding of foil with lip of container and removal of wax from foil surface. Bonding takes place at foil periphery whereas wax removal involves complete top surface of foil, plus bonding and wax removal take place at different temperatures. Such dual-purpose complex applications need proper distribution of $P_{\text {OUT }}$. However, to represent the process mathematically for commercial approval of coil design is difficult, particularly, when the foil diameter varies widely. Rather, experimental approach on a proven coil [4] would help to derive the desired coil shape. One typical coil suitable for wide range sealing is shown in Fig. 3 [2]. The coil head consists of multiple circular spiral segments (see Fig. 3) placed in three different axes to create multi-axis magnetic flux lines to improve the distribution of $P_{\text {OUT }}$ on moving foil surface. The arrangement ensures perfect sealing at high speed of wide range bottles and consume less power. It helps reduce the coil current, thereby, reducing power loss in coil as well.

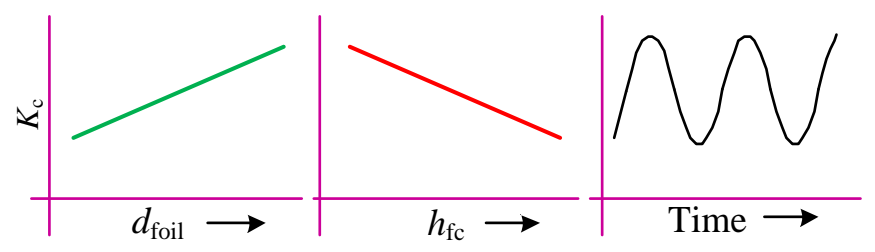

a)

b)

c)

Fig. 4: In wide range applications, process parameters influence the value of $K_{\mathrm{c}}$ in number of ways, when, a) foil diameter $d_{f \text { oil }}$ changes, b) height $h_{\mathrm{fc}}$ between foil and coil is adjusted, and, c) foil travels beneath different coil segments.

The parameter of power transfer to foil(s) $K_{\mathrm{c}}$ depends on diameter $d_{\text {foil }}$ of foil (see Fig. 4a), distance $h_{\mathrm{fc}}$ between foil and coil (see Fig. 4b) and location of moving foil relative to coil segment (Fig. 4c), it can be expressed as,

$K_{\mathrm{c}}=f\left(d_{\mathrm{foil}}, d_{\mathrm{fc}}, t\right)$

\section{TOPOLOGY FOR PERFORMANCE AND LOSS DISTRIBUTION}

Though, four parameters (1) together contribute to $P_{\text {OUT }}$, the application of load in the form of thin non-magnetic foils, does not make much impact on values of $f_{\mathrm{s}}$ and L1. For better control of sealing process, where $K_{\mathrm{c}}$ varies widely, constant coil current $i_{\mathrm{L}}$ is desired. Generally, power loss $P_{\text {comp }}$ of a component depends on its operating conditions such as voltage $V$, current $I$ and frequency $f_{\mathrm{s}}$, like, 
$P_{\text {comp }}=f\left(V, I, f_{s}\right)$

It would be ideal if $P_{\text {comp }}$ is optimally reduced. The chosen topology should be able to reduce power loss in the system and make positive influence on (1) to make $P_{\text {comp }}=f(V$ or $I)$.

Either series (see Fig. 5a) [11] or parallel configuration (see Fig. 5b) [9] of tank circuit could be used to feed the coil. Series resonant (SR) configuration is preferred because:

1. For small to moderate power applications, parallel resonant topology in half-bridge set up is bulky [10]

2. For safety isolation of load, the power control circuit in parallel resonant topology incurs more heat loss

3. Need of a greater number of power semiconductors in the frequency control circuit, even under perfect ZVZCS conditions, the conduction loss is large.

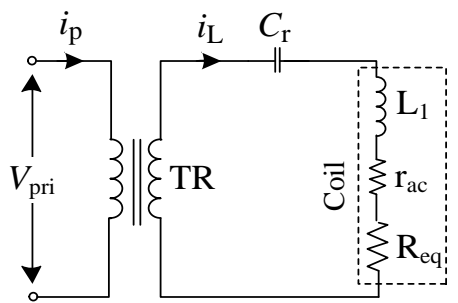

a)

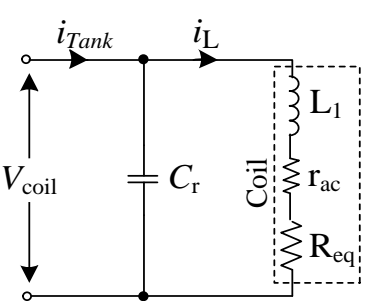

(b)
Fig. 5: a) series resonant tank circuit, and, b) parallel resonant tank circuit

\section{A. Compatibility Study of Topologies for SRI}

The chosen converter topology should be able to generate requisite process performance and ensure optimally reduced power loss. The rise in temperature of each component must be under respective safe operating limit. Under constrained free convection, not only the quantum of loss but also its distribution inside the enclosure and in heat sink is important. Among several converter topologies used for feeding series resonant tank circuit, the popularly used ones are listed below:

1. Power control by phase shifted (PS) inverter

2. Power control by pulse-density-modulation (PDM),

3. Power control by controlling the phase angle $\alpha$ between voltage and current of inverter, and,

4. Power and frequency control by chopper controlled ZVZCS topology - half bridge or full bridge.

In first three topologies mentioned above, Q1, D1 and L2 are not needed (see Fig. 1). The inverter is always fed with input voltage $V_{\mathrm{dc}}$. In most cases, SR topology inherently ensures the zero-voltage switching (ZVS) condition. For moderate power continuous-duty applications, half-bridge configuration is used where the output power $P_{\text {inv }}$ of inverter could be expressed as,

$P_{i n v} \approx 0.45 V_{d c} i_{p} \cos \alpha$

$V_{\mathrm{dc}}$ is input voltage and $i_{\mathrm{p}}$ is primary current of transformer TR. Expressions of $i_{\mathrm{p}}$, the turns-ratio $n$ of TR at rated current $i_{\mathrm{L}}$ and tank circuit impedance $Z_{\mathrm{r}}$ are,

$$
\begin{aligned}
i_{p}= & 1.1 \frac{V_{d c}}{2 n^{2} Z_{r}} \text { where, } n=\frac{n_{p}}{n_{s}}=1.1 \frac{V_{d c}}{2 Z_{r} i_{L}} \\
Z_{r}= & \left(R_{e q}+R_{s r}+r_{a c}\right)+j\left(\omega L_{1}-\frac{1}{\omega C_{r}}\right) \\
& =R_{T C}+j\left(\omega L_{1}-\frac{1}{\omega C_{r}}\right)=Z_{r} \angle \alpha
\end{aligned}
$$

$R_{\mathrm{TC}}$ is total resistance of the tank circuit, it increases when load is applied, $n_{\mathrm{p}}$ and $n_{\mathrm{s}}$ are primary and secondary turns of TR.

Accurate and efficient control of power delivered to foil is prerequisite for quality sealing of wide range bottles. The PS ZVS converter [8] is less suitable, particularly, for light load and no-load applications. Large circulating current in Mosfets and anti-parallel diodes would result large power loss in Q2, Q3. Secondly, the PS topology is mostly suitable for full bridge configuration, needs more loss-making power switching devices and associated gate drives. When the foil diameter is small or in no foil case (both valid operating conditions), there is possibility of inverter operating in hard-switched mode. The power loss would be large, needs strong heat removal means.

PDM [11] technique could be used where controlled delivery of energy to a series tank circuit is useful for applications. But it is not effective for controlled delivery of power to moving foils using multiple coil segments, placed on three different axes (see Fig. 3). Each segment is assigned with specific purpose - sealing and/or wax removal [2]. When a foil moves beneath multi-axis coil head (see Fig. 3 ), $K_{\mathrm{c}}$ (2) keeps changing with respect to time (see Fig. 4c). It would be difficult to guarantee transfer of desired quantum of energy to each specific area of foil in time. Each coil segment is designed to play certain critical role. But with PDM, when reference power is zero, there could be zero power transferred to each foil. Uncontrolled spatial distribution of power would affect the sealing quality. Bonding of foil with lip of container and or wax removal from complete top surface may not be ensured.

\begin{tabular}{|c|c|c|c|c|}
\hline \multirow[t]{2}{*}{ Inverter Topology } & \multicolumn{2}{|c|}{ ZVS } & \multicolumn{2}{|c|}{ ZVZCS } \\
\hline & No load & Full load & No load & Full load \\
\hline Inverter voltage, $\mathrm{V}$ & \multicolumn{2}{|c|}{330} & 22.0 & 280 \\
\hline Coil current $i_{\mathrm{L}}, \mathrm{A}$ & \multicolumn{4}{|c|}{70} \\
\hline $\mathrm{L} 1(\mu \mathrm{H}) ; \mathrm{Cr}(\mu \mathrm{F})$ & \multicolumn{4}{|c|}{$32.5 ; 0.36$} \\
\hline$R_{\mathrm{sr}}(\mathrm{m} \Omega) ; r_{\mathrm{ac}}(\mathrm{m} \Omega)$ & \multicolumn{4}{|c|}{$0.24,9.7$} \\
\hline Magnitude of $Z_{\mathrm{r}}, \Omega$ & 0.535 & 0.535 & 0.02 & 0.321 \\
\hline Magnitude of $R_{\mathrm{CT}}, \Omega$ & 0.02 & 0.321 & 0.02 & 0.321 \\
\hline $\mathrm{Q}, \mathrm{Q} 2$ & \multicolumn{2}{|c|}{ IXFN100N50Q3 } & \multicolumn{2}{|c|}{ IXFN100N50Q3 } \\
\hline Q3 & \multirow{3}{*}{\multicolumn{2}{|c|}{ Not applicable }} & \multicolumn{2}{|c|}{ IXFN100N50Q3 } \\
\hline D1 & & & \multirow{2}{*}{\multicolumn{2}{|c|}{$\frac{\text { DSEP 2X31-06A }}{20 \mathrm{mH}}$}} \\
\hline $\mathrm{L} 3, \mathrm{mH}$ & & & & \\
\hline Turns ratio, $n$ & \multicolumn{2}{|c|}{$4(12: 3)$} & \multicolumn{2}{|c|}{$6(12: 2)$} \\
\hline Primary current, A & \multicolumn{2}{|c|}{17.5} & \multicolumn{2}{|c|}{11.7} \\
\hline Circulating current & \multicolumn{2}{|c|}{ Large } & \multicolumn{2}{|c|}{ Negligible } \\
\hline
\end{tabular}

TABLE I

IMPACT OF TOPOLOGY ON INVERTER PARAMETERS

If power control with requisite distribution is achieved by controlling the angle $\alpha$ (4), then ZVS topology could be used for wide range sealing. It is achieved by suitably changing the frequency $f_{\mathrm{s}}$. The topology is effective if change in frequency with application of load is significant. Still, if $\alpha$ is not zero then $n$ (5) is not maximum and the current $i_{\mathrm{p}}$ would be more. The situation would be worse in no load (see Fig. 6a) or light-light conditions, the circulating current in primary would be large. The topology does not attain turn-off of Q2 and Q3 at zero current and large current flows through their respective antiparallel diodes leading to increase in power loss in packages of Q2, Q3. Moreover, the inverter loss would be concentrated on two devices. Often, the thermal resistance of anti-parallel diode is large. To make this topology workable, it needs good heat removal system. Therefore, for wide range sealing prospect, 
ZVS topology is also less suitable. For comparative study, parameters and power components of $47 \mathrm{kHz}$ ZVS half-bridge inverter for delivering $1.5 \mathrm{~kW}$ at coil current $70 \mathrm{~A}$ are listed in Table I. The calculated power loss both under no load and full load conditions are listed in Table II.

\section{B. Topology for Zero Ventilated System}

When chopper is added for power control (see Fig. 1), turning off of Q2 and Q3 is achieved near zero current right from no load condition onwards (see Fig. 6b). The inverter input voltage $V_{\mathrm{CH}}$ is accordingly adjusted. Phase lock loop and control in $V_{\mathrm{CH}}$ together help inverter frequency $f_{\mathrm{s}}$ track the resonant frequency $f_{0}$ to ensure the inverter operates in ZVZCS condition. Large value of $n$ is desired to have small current in primary side power components [21]. Here, the angle $\alpha$ is close to zero and the corresponding value of $\mathrm{Z}_{\mathrm{r}}$, at full load condition, is minimum $\left(Z_{\mathrm{r}}(\mathrm{min})\right)$ at $R_{\mathrm{TC}}$, like,

$Z_{r}(\min )=\left(R_{e q}+R_{s r}+r_{a c}\right)=R_{T C}$

With $Z_{\mathrm{r}}$ at $Z_{\mathrm{r}}(\min )$, the value of $n$ is maximum at $n_{\max }$, like,

$n_{\max }=1.1 \frac{d_{\max } V_{d c}}{2 Z_{r}(\min ) i_{L}}$

Where $d_{\max }$ is maximum PWM duty cycle of chopper. The primary current $i_{\mathrm{p}}$ could be minimum at $i_{\mathrm{p}}(\mathrm{min})$, like,

$$
i_{p}(\min )=\frac{i_{L}}{n_{\max }}
$$

The ratio of $i_{\mathrm{p}}$ in ZVZCS and ZVS topology is expressed as,

$\frac{i_{p-Z V S}}{i_{p-Z V Z C S}}=\frac{Z_{r-Z V S-F L}}{Z_{r}(\min )}>1$

$Z_{r-Z V S-F L}$ is the value of $Z_{\mathrm{r}}$ when coil in ZVS topology is fully loaded. The primary side current is less in ZVZCS inverter. Major components used in this topology are listed in Table I.

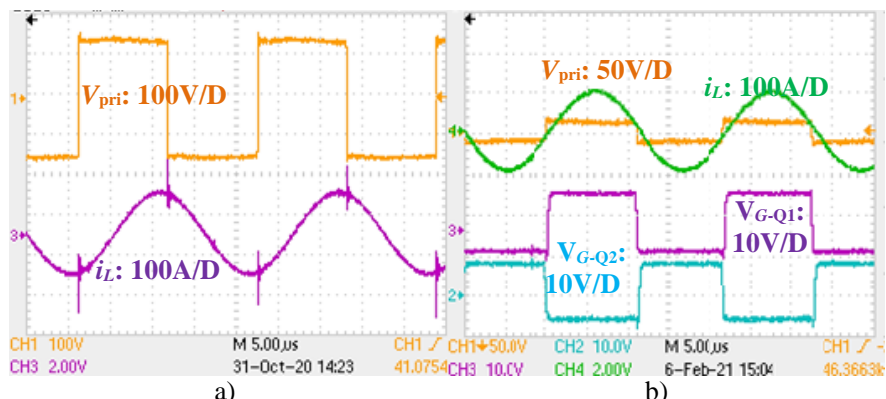

Fig. 6: Inverter output waveforms under no load condition at coil current 70 A, for, a) ZVS topology, and, b) ZVZCS topology

The power converter stage of the system is shown in Fig. 7. The resonant frequency $f_{0}$ was $46.4 \mathrm{kHz}$. For delivering $1.5 \mathrm{~kW}$ power at 70A the value of $R_{\text {eq }}$ was $0.31 \Omega$ and the value of $R_{\mathrm{TC}}$ was $0.321 \Omega$, the value of $n_{\max }$ was 6 . The set of waveforms of ZVZCS inverter at no-load, partial load and full load conditions are shown in Fig. 6b, 8a and 8b respectively. It is now clear that, except $\mathrm{L} 1$ and $C_{\mathrm{r}}, \mathrm{ZVZCS}$ topology would reduce the power loss in each HF component. But, here, three more components Q1, D1 and L2 (see Table I) are added. Comparative power losses in two topologies are mentioned in Table II. Not only the overall power loss is drastically reduced under ZVZCS topology, it is distributed over greater number of components to realize superior heat dissipation ability of the system.

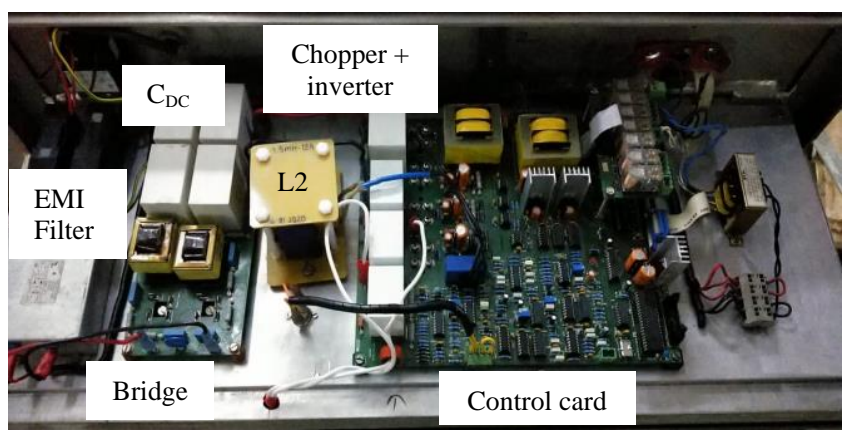

Fig. 7: Power and control circuits of experimental prototype of $50 \mathrm{kHz}, 1.5 \mathrm{~kW}$ zero-ventilated induction heating system

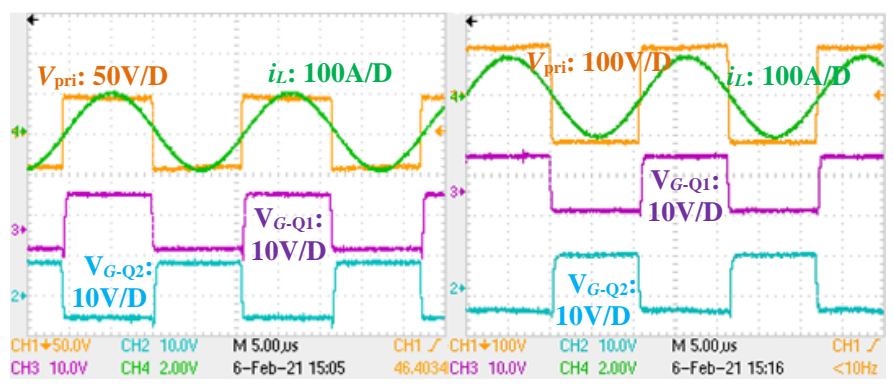

a)

b)

Fig. 8: Inverter output and gate signals, when a) 6 no. $55 \mathrm{~mm}$ dia. foils were under the coil head and, b) 3 no. $105 \mathrm{~mm}$ dia. foils were under the coil head

TABLE II

IMPACT OF TOPOLOGY ON POWER LOSS AND ITS DISTRIBUTION

\begin{tabular}{|c|c|c|c|c|}
\hline Inverter Topology & \multicolumn{2}{|c|}{ ZVS } & \multicolumn{2}{c|}{ ZVZCS } \\
\hline Load condition & No load & Full load & No load & Full load \\
\hline Loss in Q2+Q3, W & 47.0 & 45.0 & 14.7 & 15.1 \\
\hline Loss in C2 + C3, W & 0.25 & 0.25 & 0.11 & 0.11 \\
\hline Loss in TR, W & 11.0 & 11.0 & 4.0 & 6.0 \\
\hline Loss in Q1, W & Not applicable & 2.1 & 11.7 \\
\hline Loss in D1, W & Not applicable & 12.3 & 2.3 \\
\hline Loss in L2, W & Not applicable & 3.1 & 2.7 \\
\hline $\begin{array}{l}\text { Total loss in power } \\
\text { converter stage, W }\end{array}$ & 58.25 & 56.25 & 36.31 & 37.9 \\
\hline Powe loss in L1, W & \multicolumn{4}{|c|}{46.6} \\
\hline Power loss in Cr, W & \multicolumn{4}{|c|}{} \\
\hline
\end{tabular}

\section{Half-Bridge vs Full-Bridge Configuration}

Though, half-bridge configuration was used in the design, a brief comparative statement on performance with full-bridge counterpart needs certain mention. Here, in each half cycle, half the power remains unused and stored in either $\mathrm{C} 2$ or $\mathrm{C} 3$. In fullbridge set up, they are replaced by Mosfets and, for the same tank circuit load, value of $n_{\max }$ (8) gets doubled at 12:1. For same $i_{\mathrm{L}}$, current in primary side components would be reduced to half the value. The power loss in chopper circuit, BR and $L_{\mathrm{DC}}$ (see Fig. 1) would be less. If the power loss during off-state in Mosfets is ignored, then full bridge inverter would incur reduced loss everywhere except the tank circuit. Above all, distribution of power loss would be superior. To reduce the complexity full-bridge topology was avoided. It needed two more isolated gate drivers with associated power supplies.

IV. COMPONENT ENGINEERING FOR AIR-TIGHT ENCLOSURE 
Wide range of components, used in resonant inverter, could be broadly categorized as:

1. High frequency active power components

2. High frequency passive power components

3. Low frequency power components, and,

4. Components for control and gate drive circuits

In a thermally challenged system, capacity utilization of each component would have to be compromised. Derating of a component zeroes down to finding a stable worst case operating point where the temperature at its source is well below its safe operating limit. It could be achieved in several ways, such as,

1. Choose a component with reduced power loss

2. Choose one with higher ambient temperature rating

3. Choose one with lesser thermal resistance, and or,

4. Adopt a topology that helps reduce power loss.

\section{A. Choice of Component and Its Derating}

The temperature rise at source needs to be maintained below the respective safe operating limit. Removal of heat becomes difficult even when natural convection does not exist. The air movement inside the enclosure is still possible if there is differential air density caused by the existence of temperature difference in air. The approach of internal convection could be effective if the heat from each source (e.g., the junction of Mosfet, etc.) is effectively transferred to its surface to act as plume. Several components (e.g., transformer, etc.) have multiple heat sources. Therefore, choice of component could be dictated by the extent it contributes in creating significant buoyant force to assist the air movement inside.

For reliable performance of thermally challenged system the controller should be extremely efficient [15]. Power loss $P_{\text {comp }}$ in each component needs to be minimized. E.g., components incurring significant loss could be categorized into three segments - tank circuit, power converter and rectifier with filter. The case temperature $T_{\mathrm{c}}$, say, of active component with junction temperature $T_{\mathrm{j}}$ is expressed as,

$T_{j}=R_{t h} P_{\text {comp }}+T_{C}$

$R_{\text {th }}$ is its thermal resistance. For buoyant force to be effective, the differential $T_{j}-T_{c}$ should be minimum. Therefore, the criteria for choosing an active or passive component could be defined by a suitability parameter $C_{\text {comp }}$, like,

$C_{\text {comp }}=\frac{1}{R_{t h} P_{\text {Comp }}}$ or, $C_{\text {comp }}=\frac{K}{P_{\text {Comp }}}$

$K$ is thermal conductivity of a component.

A few critical components are discussed here.

\section{B. Tank Circuit Components}

Tank circuit acts as load to the power controller, it consists of capacitor $\mathrm{Cr}$ and multi-segmented coil head. The coil is housed inside the enclosure and virtually decides the size of the power controller. Irrespective of quantum of energy transferred to foil, the rated sinusoidal current $i_{\mathrm{L}}$ flows through $\mathrm{C}_{\mathrm{r}}$ and L1. Total power loss in tank circuit consists of loss $P_{\mathrm{L} 1}$ in $\mathrm{L} 1$ and $P_{\mathrm{Cr}}$ in $\mathrm{Cr}$, each one is expressed as,

$P_{L 1}=i_{L}^{2} r_{\mathrm{ac}}$ and $P_{C r}=i_{L}^{2} R_{\mathrm{sr}}$

$\mathrm{AC}$ resistance $r_{\mathrm{ac}}$ of $\mathrm{L} 1$ is $r_{\mathrm{ac}}=r_{\mathrm{ac} 1}+r_{\mathrm{ac} 2}+r_{\mathrm{ac} 3}+r_{\mathrm{ac} 4}$.
The value of, say, $r_{\mathrm{ac} 1}$ depends on number of turns in it, length $l_{1}$ of litz-wire conductor used, diameter $d_{\mathrm{s}}$ of each strand, frequency $f_{\mathrm{s}}$ of coil current and coil geometry. When $d_{\mathrm{s}}$ is much less than the skin depth, the impact of skin effect on conductor is neglected, but proximity effect could still be effective. To include the impact of spatial distribution of magnetic field, the expression [20] resistance $r_{\mathrm{acl}}$ of, say, L1-1 with $n_{l}$ turns is,

$r_{\mathrm{ac} 1} \approx r_{\mathrm{dc} 1}+r_{\mathrm{ind} 1} \approx \frac{4 \rho l_{1}}{n_{2} \pi d_{s}^{2}}+n_{2} \frac{\pi^{4} d_{s}^{4} f_{s}^{2}}{8 \rho} \sum_{1}^{n_{1}}\left\lfloor r_{i}\left\langle B_{i}^{2}\right\rangle\right\rfloor$

Where $r_{\mathrm{dc} 1}$ is dc resistance of $\mathrm{L} 1-1, \rho$ is resistivity of copper and $r_{\text {ind } 1}$ is contributed by proximity effect. $B_{\mathrm{i}}$ is the average flux density encompassing the $i^{\text {th }}$ turn, $n_{2}$ is number of strands of litz wire conductor.

The impact of proximity effect on, say, $r_{\mathrm{ac} 1}$ is not uniform, it is peak at center because here the value of $B$ is maximum. In the design, multi-segmented coil is adopted to meet the wide range sealing prospects. Laterally, it helps reduce the impact of proximity effect, because the peak of $B$ in each segment is considerably less. The prospect of creation of hot spot is thereby reduced. The value of $r_{\text {ind }}$ is maximum when the coil is not loaded [20]. Application of load would reduce the peak value of $B$. The impact of thin aluminum foil as load on $B$ could be gauged by placing a search coil at the center of a coil segment. Fig. 9a shows the induced voltage in it when the coil was not loaded, in Fig. 9b the coil was loaded to its capacity. There was reduction of $20 \%$ in induced voltage. The proximity loss is also reduced at elevated temperature of strands. If, compared to skin depth $(0.291 \mathrm{~mm}$, at $50 \mathrm{kHz})$, the value of $d_{\mathrm{s}}(0.1 \mathrm{~mm})$ is chosen significantly small, the contribution of $R_{\text {ind }}$ on $r_{\text {ac1 }}$ would be less. Here, the value of $r_{\mathrm{dc}}$ was $7.5 \mathrm{~m} \Omega$ and after 6 -hr heat run its measured value was $8.8 \mathrm{~m} \Omega$ and the value $r_{\mathrm{ac}}$ considered was $9.7 \mathrm{~m} \Omega$ [20]. The value of PL1 at current density $2.36 \mathrm{~A} / \mathrm{mm}^{2}$ was $47.6 \mathrm{~W}$, each segment power loss was $11.9 \mathrm{~W}$.

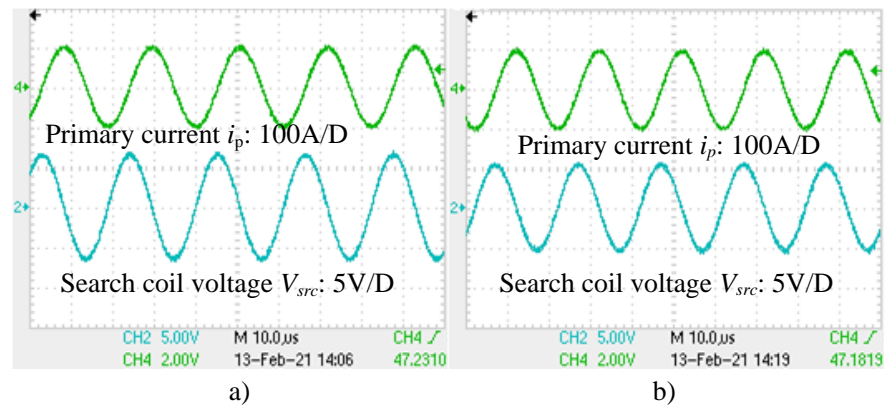

Fig. 9: Search coil voltage at constant coil current, when, a) L1 was not loaded, and, b) there was dip in voltage when L1 was fully loaded.

For constant coil current, $P_{\mathrm{Cr}}(13)$ remains constant. Its value for polypropylene dielectric is less. To boost the value of $C_{\mathrm{Cr}}$ (12) further, conduction cooled capacitors are preferred. Due to superior terminals, in the form of copper plates on either side, the values of both $R_{\mathrm{sr}}$ and $R_{\mathrm{th}}$ are much reduced.

\section{Inverter Transformer}

Transformer TR (see Fig. 1) is an integral part of SRI topology, it is used to provide necessary current multiplication, safety isolation. The design of HF TR to be housed in an airtight enclosure is complex because there exist multiple heat sources - in cores and in two windings. Losses in core $P_{\text {core }}$ and in windings $P_{\mathrm{cu}}$ are expressed as [21], 


$$
P_{\text {core }}=W_{\text {core }} K_{S} f_{S}^{\alpha} B_{m}^{\beta} \text { and } P_{\text {cu }}=i_{L}^{2}\left(\frac{R_{\text {pri }}}{n^{2}}+R_{\text {sec }}\right)
$$

$W_{\text {core }}$ is core weight. $K_{\mathrm{S}}, \alpha$ and $\beta$ are Steinmetz parameters. $R_{\text {pri }}$ and $R_{\text {sec }}$ respectively are resistance of primary and secondary windings. For cap sealing, the windings draw rated current always. The value of $P_{\text {cu }}$ is always at rated value. $P_{\text {core }}$ varies with delivered power $P_{\text {OUT }}$ [21]. Peak flux density $B_{\mathrm{m}}$ in core is,

$B_{m}=\frac{V_{\text {pri }}}{4 n_{p} A_{\text {core } f_{s}}}=\frac{V_{\mathrm{CH}}}{8 n_{p} A_{\text {core } f_{s}}}$

$A_{\text {core }}$ is core area, $V_{\text {pri }}$ is primary voltage of TR. $V_{\mathrm{CH}}$ is output voltage of chopper controller, its value increase with load $R_{\text {eq. }}$. The expression of square wave $V_{\text {pri }}[21]$ is,

$V_{\mathrm{pri}}=0.9 n\left(r_{\mathrm{ac}}+R_{\mathrm{sr}}+R_{\mathrm{eq}}\right) i_{L}$

For suitability of TR the value of $C_{\mathrm{TR}}$ (12) should be maximized, it could be achieved through following means:

1. Both core and copper loss should be minimum

2. ZVZCS helps maximize the value of $n$ at $n_{\max }$ (8) where the value of $P_{\mathrm{cu}}$ is minimum, current in primary and copper length at secondary are minimized, and,

3. The value of $K(12)$ of core material should be large.

TABLE III

COMPARATIVE PARAMETERS TO FIND SUITABLITY OF TR

\begin{tabular}{|c|c|c|c|}
\hline Material & P Grade & FT 3M & N87 \\
\hline Type & Ferrite & Nanocrystalline & Ferrite \\
\hline Manufacturer & Magnetics Inc. & Hitachi & TDK \\
\hline Permeability $\mu_{\mathrm{r}}$ & 2500 & $>40000$ at $0.1 \mathrm{~T}$ & 2200 \\
\hline$B_{\mathrm{m}}$ when loaded, T & 0.083 & 0.089 & 0.096 \\
\hline No. of cores stacked & 4 & 3 & 3 \\
\hline Volume of core, cm $\mathrm{cm}^{3}$ & 162.33 & 143.2 & 139.0 \\
\hline$P_{\text {Core }}$ at $50 \mathrm{kHz}, \mathrm{W}$ & 3.1 & 2.95 & 2.36 \\
\hline Th. cond. $K, \mathrm{~W} / \mathrm{mK}$ & 4.3 & 10 & 5 \\
\hline $\begin{array}{c}\text { Minimum length of } \\
\text { copper/turn, } \mathrm{cm}\end{array}$ & 26.7 & 26.2 & 22.3 \\
\hline$P_{\mathrm{cu}}$ at $i_{\mathrm{L}}=70 \mathrm{~A}, \mathrm{~W}$ & 4.1 & 4.1 & 3.6 \\
\hline
\end{tabular}

Note: The core loss is for sinusoidal excitation (15)

Features of transformer using different core materials are listed in Table III. Though, due to large $K$, nanocrystalline cores could be suitable [22], but due to minimum total power loss along with moderate value of $K$, the $\mathrm{N} 87$ grade ferrite was preferred.

\section{Power Devices and Gate Drive}

Apart from tank circuit, another important part incurring large loss in the system is the power converter, it controls the power delivery to foil at desired high frequency. It is clear now that ZVZCS topology achieves two important goals minimizes the power loss in HF power converter segment and offers better distribution of it (see Table II). With addition of number of active and passive components, the power loss per component is reduced to boost both the parameters $P_{\text {Comp }}$ and $R_{\text {th. }}$. The design now needs to decide suitable low-loss HF power devices to drive the power converter and incurs minimum loss in $P_{\mathrm{Q} 1-\mathrm{Q} 3}$ and $P_{\mathrm{D} 1}$ and also ensures that they possess small value of $R_{\mathrm{th}}$. Suitable power devices for Q1-Q3 could be IGBT, Mosfet or SiC Mosfet. For ZVZCS inverter, the comparative statement of three different component types is listed in Table IV. IGBT is less suitable because of large power loss, poor value of $R_{\text {th }}$ and it requires more gate drive power [23]. It is clear that Mosfet IXFN100N50Q3 is more suitable because, though, it incurs moderate power loss. But due to its minimum $R_{\mathrm{th}}$ value, $T_{j}-T_{c}$ would be less. The Mosfet requires small gate power as well. Due to same value of $R_{\text {th }}$ of anti-parallel diode, Mosfet could be treated as single heat source in any application. SiC Mosfet is costliest and have large $R_{\text {th }}$.

TABLE IV

SUITABLITY OF ACTIVE DEVICES AT AC CURRENT 11.7A

\begin{tabular}{|c|c|c|c|}
\hline Material & IGBT & SiC Mosfet & Mosfet \\
\hline Component in ISOTOP package & $\begin{array}{c}\text { STGE50 } \\
\text { NC60VD }\end{array}$ & $\begin{array}{c}\text { GCMS040 } \\
\text { A120S1 }\end{array}$ & $\begin{array}{c}\text { IXFN100 } \\
\text { N50Q3 }\end{array}$ \\
\hline $\begin{array}{c}\text { Current rating at } 25^{\circ} \mathrm{C}, \mathrm{A} \\
\text { Power loss in Q2+Q3 in perfect } \\
\text { ZVZCS condition @ 11.7A, W }\end{array}$ & 17.3 & 60 & 80 \\
\hline$R_{\text {th }}$ of switch, ${ }^{\circ} \mathrm{C} / \mathrm{W}$ & 0.48 & 0.6 & 14.7 \\
\hline$R_{\text {th }}$ of diode, ${ }^{\circ} \mathrm{C} / \mathrm{W}$ & 1.5 & 0.65 & 0.13 \\
\hline$C_{\text {Comp }}$ of Q2, Q3 in ZVZCS & 0.241 & 0.29 & 1.046 \\
\hline Gate power, W & 0.27 & 0.15 & 0.16 \\
\hline
\end{tabular}

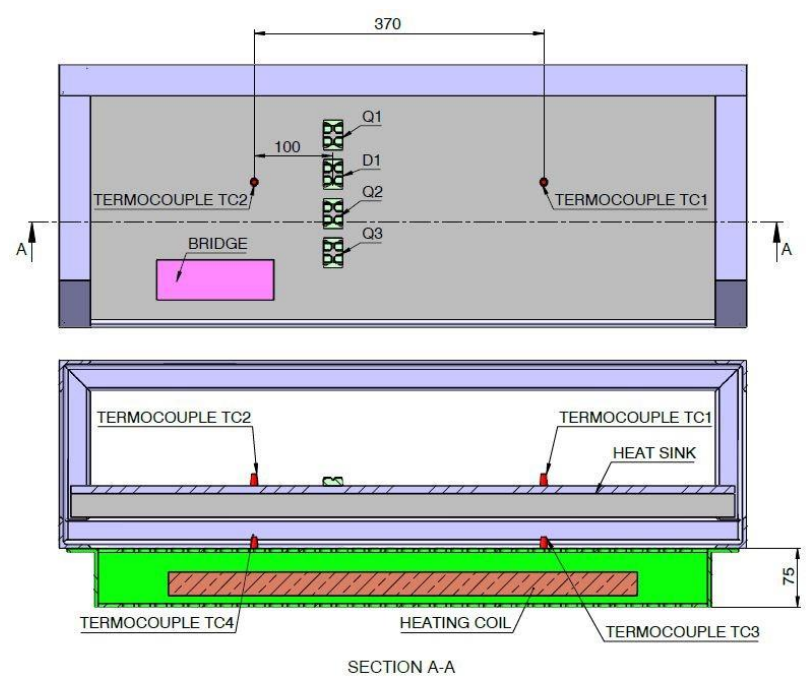

Fig. 10: Internal temperature distribution when the coil was not loaded

\section{E. Low Frequency Components Plus Control Circuit}

Apart from tank circuit and power converter, other areas that incur power loss are BRIDGE, filter circuit in DC-link, PCB and power supplies for control and gate drive circuits. When MKP capacitors are used in DC link [24] and for $C_{\mathrm{DC}}$ $>0.5 \mu \mathrm{F} / \mathrm{W}$, power loss in it could be ignored (esr is small). Significant power loss would be in BRIDGE. At full load, the average value of current in DC link was 10.5A. When two 35A bridge rectifiers were connected in parallel, the power loss in it was reduced by $9 \%$ to $8.3 \mathrm{~W}$ and the value of $R_{\text {th }}$ was reduced to half. BRIDGE assembly was placed on heat sink. On the other hand, components in control circuit were rated for $105{ }^{0} \mathrm{C}$ ambient or above. The power loss in PCB was handled through proper layout where width of tracks was $25 \%$ more than normal and pad area for components (e.g., integrated circuits, etc.) [25] was increased by $20 \%$.

\section{V.Product Validation Through Heat Run Test}

For experimental validation, one $1.5 \mathrm{~kW}, 47 \mathrm{kHz}$ power controller suitable for wide range sealing applications was developed. Including the multi-head coil head, each component was housed inside the IP 65 enclosure. Prolonged heat run test was planned to verify the design for long-term continuous-duty 
use. The loss characteristics of ZVZCS converter was a little different from conventional controllers. The load current was always kept constant where stress on a few components was maximum under no load condition. E.g., power loss in L1 was maximum at no load [20]. Similar situation existed for diode D1. The value of $R_{\mathrm{th}}$ of D1 was more than that of Q1-Q3. When power was increasingly drawn through $\mathrm{L} 1$, the duty cycle of $\mathrm{Q} 1$ increased and that of D3 decreased. The power loss in Q1 would go up whose $R_{\text {th }}$ value was much less than that of D1. Therefore, to ensure testing under respective worst-case situation of each component, the power controller was put on for heat run test both under no load and full load conditions. To draw power through coil L1, a water-cooled non-magnetic plate was placed beneath. The quantum of power drawn was varied by adjusting the vertical distance between L1 and water-cooled plate.

As shown in Table II the power loss characteristics of the system was complex where wide range of active and passive components were used. Active components were placed on heat sink (see Fig. 10) and passive components were placed inside the enclosure in different layers where L1 was placed at the bottom of the enclosed system. To measure and record the temperature profile during heat run test, six-channel temperature recorder (CHINO Corporation, Model: AH 4706NOA-NNN) was used. As detailed in Fig. 10, four thermal probes were used. Two of them placed on the heat sinks and other two were placed in the air between the heat sink and coil.

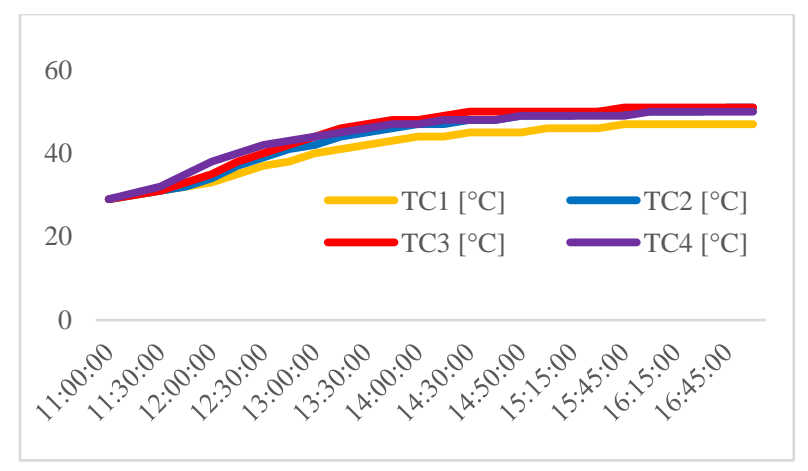

Fig. 11: Internal temperature distribution when the coil was not loaded

For performance testing the equipment was kept ON till the temperature reading of all four probes got stabilized. The ambient temperature recorded was $29.5^{\circ} \mathrm{C}$. Fig. 11 shows the temperature profile of four probes when the coil was not loaded. The maximum temperature rise of $23.5{ }^{\circ} \mathrm{C}$ was recorded on TC2 placed on heat sink close to Q1-Q3 and D1. The corresponding rise in temperature (TC4) of internal ambient below TC2 was nearly same at $23.0{ }^{\circ} \mathrm{C}$. The temperature rise of heat sink on other side (TC1) was less at $21.5^{\circ} \mathrm{C}$. Soon after the test was completed the temperature of TR, L1 and L2 were measured using infra-red thermometer (Fluke make: 59 Mini IR Thermometer), they are listed in Table V.

Fig. 12 shows the temperature profile of four probes when the coil was fully loaded. The maximum temperature rise of $24.5^{\circ} \mathrm{C}$ was recorded on $\mathrm{TC} 2$. The corresponding rise in inside ambient temperature was $23.0^{\circ} \mathrm{C}$. The measured temperature of $\mathrm{TR}, \mathrm{L} 1$ and $\mathrm{L} 2$ are listed in Table V.

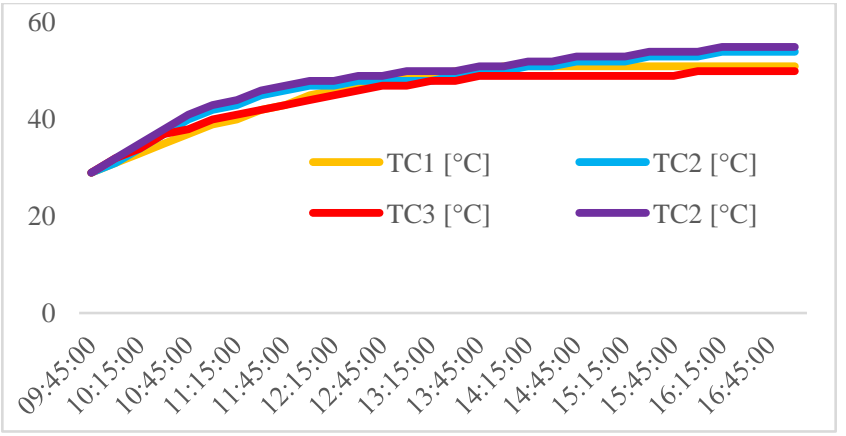

Fig. 12: Internal temperature distribution when the coil was loaded

TABLE V

MAXIMUM STEADY STATE TEMPERATURE OF CRITICAL ITEMS

\begin{tabular}{|c|c|c|c|c|c|}
\hline Component & Q1-Q3 & Ambience & TR & L1 & L2 \\
\hline Temp. at no load, ${ }^{0} \mathrm{C}$ & 53.0 & 52.0 & 68.0 & 75 & 77 \\
\hline Temp. at full load, ${ }^{0} \mathrm{C}$ & 54.0 & 52.5 & 71.0 & 73 & 76 \\
\hline
\end{tabular}

It is clear that the zone-wise shift in temperature-rise recorded under no-load and full load conditions was minimal. ZVZCS topology at constant coil current played major role. The total power loss mostly remained constant throughout the loading conditions. Marginal increase in temperature at full load was due to increase in loss in BRIDGE and TR. Maximum temperature noted on surface of each active and passive power components would signify that each component was well under the respective safe operating limit. With internal ambience at little above $50{ }^{\circ} \mathrm{C}$ meant that the controller could be used for continuous duty applications under any load conditions.

\section{CONCLUSION}

This article highlighted that, for thermally challenged air-tight induction heating system, the mode of heat removal, particularly, from passive components was through restricted internal convection mostly contributed by buoyant force created through temperature gradient of air inside. It also detailed that for reliable operation of the system the power loss should be minimized and for effective buoyancy driven heat removal the surface temperature of each passive component, in particular, should be kept large - together they decide the derating factor of each component. The article also addressed that ZVZCS topology was useful not only to reduce the power loss in the system, but also helped distribute the loss over a greater number of components, thereby, improving the heat removal features of the system. The thermal stress on each component was substantially reduced. The proposed design was validated in 1.5 $\mathrm{kW}, 50 \mathrm{kHz}$ induction heating system at two extreme loading conditions and it was found that the temperature was close to uniform inside the enclosure. The rise of temperature of the system and also of each component were well within the respective operating limits.

\section{REFERENCES}

[1] K. J. Herzog, "Air-cooled induction foil cap sealer", U.S. Patent No. 6,633,480, 14 October 2003.

[2] A. K. Paul and S. Chinoy, "Air cooled induction heater for efficient sealing of containers using wide range foils," IEEE Trans. Ind. Appln., vol. 52, no. 2, pp. 3398-3407, Jul./Aug. 2016. 
[3] J. H. Simcock, "Multiple zone induction heating", US patent, no. 5059762, Oct. 22, 1991.

[4] A, K. Paul, "Inverter topology for zero-ventilated induction heating system," in Conf. Proc. IEEE PEDES, Jaipur, India, pp. 1-6, 2020.

[5] B. J. Knauf, D. P. Webb, C. Liu and P. P. Conway, "Low frequency induction heating (LFIH) for the sealing of plastic micro fluidic systems", Micro fluidics and Nano fluidics, 2009, pp. $1-11$.

[6] A. K. Paul, "Robust control by SOSM facilitates optimizing under actuated induction cap sealing process," IEEE Trans. Ind. Electron., vol. 64(6), pp. 4511-4519, Jun. 2017.

[7] O. Lucia, P. Maussion, E. J. Dede and J. M. Burdio, "Induction heating technology and its applications: Past developments, current technology, and future trends," IEEE Trans. Ind. Electron, vol. 61, no. 5, 2014, pp. 2509 -2520 , May 2014.

[8] D. N. Sankhe, R. R. Sawant and Y. S. Rao, "FPGA-based Hybrid Control Strategy for Resonant Inverter in Induction Heating Applications," in IEEE Journal of Emerging and Selected Topics in Industrial Electronics, doi: 10.1109/JESTIE.2021.3051584.

[9] S. Bottari, L. Malesani, P. Tenti: "High efficiency $200 \mathrm{kHz}$ inverter for induction heating applications," in IEEE PESC Conf. Record, 1985, pp. 308-316.

[10] Y. Başkurt and H. Karaca, "Evaluation of half-bridge resonant inverter topologies," Dokuz Eylul Univ. Faculty of Engg. Journal of Science and Engineering, 22(65), pp. 505-515, 2020.

[11] H. Fujita, H. Akagi, K. Sano, K. Mita and R. H. Leonard, "Pulse density modulation based power control of a $4 \mathrm{~kW} 400 \mathrm{kHz}$ voltage-source inverter for induction heating applications," in Conf. Record Power Conversion Conference, Yokohama, pp. 111-116, IEEE, 1993.

[12] D. Christen, M. Stojadinovic and J. Biela, "Energy efficient heat sink design: Natural versus forced convection cooling," IEEE Trans. Power Electron., 32(11), pp. 8693-8704, 2016.

[13] P. F. Linden and P. Cooper, "Multiple sources of buoyancy in a naturally ventilated enclosure," J. Fluid Mech., vol. 311, pp. 177-192, 1996.

[14] G. R. Hunt and P. F. Linden, "The fluid mechanics of natural ventilation displacement ventilation by buoyancy-driven flows assisted by wind," Building and Environment, vol. 34, pp. 707-720, 1999.

[15] Y. Wang, S. W. H. De Haan and J. A. Ferreira, "Potential of improving PWM converter power density with advanced components," in Conf. Proc. 13th European Power Electron. \& Applns, EPE'09. pp. 1-10, IEEE, 2009.

[16] H. Wang and F. Blaabjerg, "Reliability of capacitors for DC-link applications in power electronic converters-An overview," IEEE Trans. Ind. Appln., 50(5), pp.3569-3578, 2014.

[17] J. W. Kolar, F. Krismer, Y. Lobsiger, J. Muhlethaler, T. Nussbaumer, and J. Minibock, "Extreme efficiency power electronics", IEEE Conf. Proc. CIPS, 2012, 2012, pp. 1-22.

[18] X. Meng, J. Jhu, X. Wei and Y. Yan, "Natural convection heat transfer of a straight-fin heat sink," International Journal of Heat and Mass Transfer, pp. 273-278, Aug. 2018, Elsevier.

[19] A. K. Paul, "Emulating full load testing of air-cooled nanocrystalline IHT at zero power," in IEEE Journal of Emerging and Selected Topics in Industrial Electronics, doi: 10.1109/JESTIE.2021.3095022.

[20] J. Acero, P. J. Hernandez, J. M. Burdio, R. Alonso and L. A. Barragan, "Simple resistance calculation in litz-wire planar windings for induction cooking appliances," IEEE Trans. Mag., 41(4), pp. 587-592, Aug. 2005.

[21] A. K. Paul, "ZVZCS SRI guides optimal use of copper and core for aircooled nanocrystalline transformer for induction heating," IEEE Trans. Ind. Appln., vol. 56, pp. 561-568, Mar/Apr 2020.

[22] W. Shen, F. Wang, D. Boroyevich and C. Wesley, "High-density nanocrystalline core transformer for high-frequency resonant converter," IEEE Trans. Ind. Appln., vol. 44, no. 1, pp. 213-222, Jan./Feb. 2008.

[23] "IGBT and MOSFET drivers correctly calculated," Power Integrations Application Note AN 1001, pp. 1-7, 2016.

[24] H. Wang and F. Blaabjerg, "Reliability of capacitors for DC-link applications in power electronic converters-An overview," IEEE Trans. Ind. Appln., 50(5), pp. 3569-3578, 2014.

[25] "Semiconductor and IC package thermal metrics," Texas Instruments Application Report SPRA953C, pp. 1-15, 2016. 